conducting media. The fifth treats of electric currents in a conducting sphere with and without an external magnetic field, and the sixth, which is the longest in the book, gives a very full discussion of diffraction and scattering with special reference to the nature of the disturbance near the edge of the shadow and in the neighbourhood of caustics. The seventh and eighth deal with radiation and resonance and material systems in motion.

Quite apart from the frequently novel methods employed, the book is a very useful compendium of recent work on electromagnetism. It is well printed and produced and is commendably free from misprints, considering the often complicated character of the formulæ employed.

\section{Tannin Chemistry}

The Natural Organic Tannins : History, Chemistry, Distribution. By Dr. M. Nierenstein. Pp. vii + 319. (London: J. and A. Churchill, 1934.) $21 s$.

$\mathrm{T}$ HE historical studies of Dr. Nierenstein, who is an authority on the history of the tannins, must be of interest to all workers on the chemistry of tannins and of leather. To read how closely Tachenius in 1677 foreshadowed recent work on the rotting of ink-dyed leather is a valuable reminder of the length of time which elapses between suggestion and proof in this branch of chemistry.

In dealing with the organic chemistry of the tannins, Dr. Nierenstein gives a useful description of existing knowledge, somewhat obscured by a detailed account of the controversies between the rival schools of Nierenstein and of Fischer and Freudenberg. It is doubtful whether the differences at issue in the catechin group are of sufficient importance to require detailed description in a general treatise. The discussion of the constitution of the gallotannins, however, makes it clear that some of the conclusions of the German school must be regarded with doubt, yet, as Dr. Nierenstein himself points out, his suggested formula for glucosidic gallotannin is not far removed from formulæ which Freudenberg admits as possibilities. It is not easy to reject the larger volume of evidence that glucose is an essential part of the gallotannin molecule on the grounds of the few reported observations of the occurrence of the tannin free from glucose. References to "the glucose spectre, haunting the chemistry ... of gallotannin" and to the glucoside hypothesis as a "stumbling block" are unduly strongly worded.
From the practical point of view of the tanner, the significant difference between the two classes of tannins is that the pyrogallol tans contain more ionisable hydrogen atoms and therefore have a more acid reaction than the catechol tans. Variations between the action of different tans of the same class are to a large extent due to differences in the size of the tannin particles in solution. The physical chemistry of the tannins requires as much attention as has been devoted to their organic chemistry. Perhaps in future editions Dr. Nierenstein, and other writers on the chemistry of the tannins, will give some account of information which is already available on this aspect of the subject.

The botanical section, written by Dr. MacGregor Skene, collects the existing knowledge of the distribution, behaviour and functions of tannin in the plant. This useful summary contains some interesting suggestions. If the catechol tannins are related to the anthocyanins, and play a part in metabolism, while the gallotannins are excretory products, it is an attractive speculation that the initial by-products of metabolism are rendered harmless by combination with glucose. Perhaps 'glucose siren' would be a more appropriate expression than 'glucose spectre'. The charmer is too seductive to be dismissed lightly, and the time has not yet come when we must stop our ears, in spite of the Ulyssean warnings of Dr. Nierenstein.

D. JORDAN LLOYD

\section{Evolution of Ideas of Space}

The Differential Invariants of Generalised Spaces. By Prof. Tracy Yerkes Thomas. Pp. $\mathrm{x}+241$. (Cambridge: At the University Press, 1934.) $21 s$. net.

THE subject of this book is extremely difficult for the general scientific reader. Even what seem to be familiar words, such as space and parallel, are used in such generalised senses that they become more puzzling than entirely new terms. This is the result of a process of evolution, and can be understood only by recalling the history of these ideas.

For the Greeks, the rigid body was fundamental, and space was mere emptiness containing it. Geometry expressed the properties of rigid bodies such as measuring rods, including the properties of congruence, established by superposition. Thus geometry was primarily a physical science, but it was reduced to a deductive form, based on a small number of axioms which, with the exception of that relating to parallels, could plausibly be regarded as self-evident truths. The idea of space as consisting of points was reached 